\title{
LESSON STUDY SEBAGAI LEARNING COMMUNITY UNTUK MENINGKATKAN KOMPETENSI PROFESIONALITAS PESERTA PROGRAM PENDIDIKAN PROFESI GURU KIMIA FKIP UNIVERSITAS RIAU
}

\author{
Maria Erna ${ }^{(1)^{*}}$, Diana Tejawati ${ }^{(2)}$, Ade Achmadi ${ }^{(3)}$, Leo F Manalu ${ }^{(3)}$ dan Martina \\ Eka Desvita ${ }^{(3)}$ \\ ${ }^{(1)}$ Program Studi Pendidikan Kimia FKIP Universitas Riau \\ ${ }^{(2)}$ Guru Kimia SMAN 12 Pekanbaru \\ ${ }^{(3)}$ Peserta Program Profesi Guru Pendidikan Kimia FKIP Universitas Riau \\ E-mail : bun_erna@yahoo.com
}

\begin{abstract}
Research on the ability of participants Professional Teacher Education Program (TEP) Chemistry FKIP University of Riau in implementing have been done Lesson Study (LS) as the Learning Community (LC) with the aim of improving professional competence as chemistry teacher candidates. The number of participants total 3 TEP guided implement the LSLC in Chemistry Laboratory FKIP and application implemented in SMAN 12 Pekanbaru. Learning implementation plan compiled by participants of TEP Chemistry Education has improved the category of B (Good) on the plan I and II to A (Very Good) on plan III. Value competence participants TEP Chemistry Education in the implementation of learning also showed an improvement of category $\mathrm{K}$ (Less) on the open lesson I and II into a C (Enough) in the open lesson III. The results of this study prove that the application LSLC at SMAN 12 Pekanbaru can develop professional competence of participants TEP Chemistry Education FKIP University of Riau in a sustainable and secure the rights of all students to get a high quality education.
\end{abstract}

Keywords: High quality education, Competence, Learning community, Lesson study

\begin{abstract}
Abstrak
Telah dilakukan penelitian tentang kemampuan peserta Program Pendidikan Profesi Guru (PPG) Kimia FKIP Universiatas Riau dalam menerapkan Lesson Study (LS) sebagai Learning Community $(L C)$ dengan tujuan meningkatkan kompetensi profesionalitas sebagai calon guru kimia. Jumlah peserta PPG berjumlah 3 orang yang dibimbing menerapkan LSLC di Laboratorium Kimia FKIP dan penerapannya dilaksanakan di SMAN 12 Pekanbaru. Hasil analisis penilaian RPP (Rencana Pelaksanaan Pembelajaran) yang disusun peserta PPG Pendidikan Kimia mengalami peningkatan kategori dari B (Baik) pada plan I dan II menjadi A (Amat Baik) pada plan III. Nilai kompetensi peserta PPG Pendidikan Kimia dalam pelaksanaan pembelajaran juga menunjukkan peningkatan dari kategori $\mathrm{K}$ (Kurang) pada open lesson I dan II menjadi C (Cukup) pada open lesson III. Hasil penelitian ini membuktikan bahwa penerapan LSLC di SMAN 12 Pekanbaru dapat mengembangkan kompetensi profesionalitas peserta PPG Pendidikan Kimia FKIP Universitas Riau secara berkelanjutan dan dapat menjamin hak semua siswa untuk mendapatkan pembelajaran bermutu tinggi.
\end{abstract}

Kata kunci: Pembelajaran bermutu tinggi, Kompetensi, Learning community, Lesson study 


\section{PENDAHULUAN}

Program Studi Pendidikan Kimia Fakultas Keguruan dan Ilmu Pendidikan FKIP Universiatas Riau merupakan salah satu program studi yang menyelenggarakan Program Pendidikan Profesi Guru (PPG). Adapun tujuan PPG adalah untuk menghasilkan calon guru yang memiliki kompetensi dalam merencanakan, melaksanakan dan menilai pembelajaran, menindaklanjuti hasil belajar, melakukan pembimbingan, dan pelatihan peserta didik serta melakukan penelitian, dan mampu mengembangkan profesionalitas secara berkelanjutan (Panduan pelaksanaan praktek pengalaman lapangan).

Pengembangkan sistem pendidikan yang berkualitas perlu dilakukan agar menghasilkan calon guru yang bermutu tinggi dan profesional. Salah satu upaya yang dapat dilakukan oleh dosen pembimbing untuk menghasilkan calon guru berkualitas tinggi adalah dengan cara menerapkan Lesson Study (LS) pada saat pelaksanaan praktek mengajar di sekolah. LS menyediakan suatu cara bagi calon guru untuk dapat memperbaiki pembelajaran secara sistematis. LS merupakan proses untuk berkolaborasi dan merancang lesson (pembelajaran) dan mengevaluasi kesuksesan strategi-strategi mengajar yang telah diterapkan sebagai upaya meningkatkan proses dan perolehan belajar siswa. Implementasi LS dapat mendorong calon guru umtuk selalu berinovasi untuk meningkatkan kualitas pembelajaran sehingga calon guru terbiasa untuk berfikir dan dapat menerapkan LS pada saat melakukan praktek pengajaran di sekolah-sekolah.

Pelaksanaan LS juga membiasakan calon guru bekerja sama untuk merencanakan, melaksanakan dan mengamati suatu pembelajaran yang dikembangkannya secara kolaboratif. Penerapan tahap-tahap LS dapat merupakan wahana untuk mengembalikan guru kepada budaya mengajar yang proporsional.

Pada penelitian ini dilakukan analisis perangkat pembelajaran yang sudah disusun oleh peserta PPG Kimia Fkip Universitas Riau dan analisis lembar observasi pada pelaksanaan pembelajaran. Diharapkan peserta PPG Kimia dapat menerapkan Lesson Study (LS) sebagai Learning Community ( $L C)$ yaitu pembelajaran bersifat otentik, kolaboratif yaitu hubungan saling mendengar, saling bantu dibantu dan saling menyimak serta adanya tugas yang bersifat melompat (jumping task). Penerapan LSLC dapat menjamin hak semua siswa untuk mendapatkan pembelajaran bermutu tinggi. Pelaksanaan LSLC akan membiasakan peserta PPG kimia melakukan Lesson Design terlebih dahulu baik secara individu maupun berkelompok dengan koleganya serta 
terbiasa menganalisis Lesson Learned setelah melakukan Open Lesson, sehingga profesionalitas peserta PPG kimia jika sudah menjadi guru dapat berkembangan secara berkelanjutan dan mandiri.

\section{METODE PENELITIAN}

Waktu kajian/penelitian dilaksanakan mulai bulan Agustus - November 2015, di Laboratorium Pendidikan Kimia FKIP UR dan SMAN 12 Pekanbaru, Provinsi Riau. Adapun sasaran kajian/subjek penelitian adalah Peserta Program Pendidikan Profesi Guru (PPG) Pendidikan Kimia Tahun 2015 yang melaksanakan Program Pengalaman Lapangan (PPL) yaitu praktek mengajar di SMAN 12 Pekanbaru yang berjumlah 3 orang.

Metode penelitian ini bersifat kuantitatif dan kualitatif dengan instrument penelitian berupa perangkat pembelajaran yang dibuat peserta PPG dan lembaran observasi pada tahap open lesson. Adapun langkah-langkah penelitian yang telah dilakukan sebagai berikut:

1. Melakukan pembimbingan terhadap peserta PPG kimia dalam menerapkan LSLC disekolah tempat praktek pelaksanaan mengajar.

2. Menganalisis hasil dokumentasi tahap-tahap $L S L C$ yang diterapkan oleh peserta PPG yaitu pada tahap plan, open lesson dan refleksi yang dilakukan dalam 3x siklus

3. Menilai perangkat pembelajaran yang dibuat peserta PPG pada tahap plan

4. Menilai setiap peserta PPG pada tahap open lesson dengan menggunakan lembaran observasi

5. Melakukan dokumentasi dan mengganalisis tahap refleksi untuk meninjak lanjuti pembelajaran berikutnya dengan arahan pembimbing.

\section{Teknik pengumpulan data}

a. Data kuantitatif (nilai perangkat perencanaan pembelajaran dan observasi open lesson)

1. Analisis kemampuan peserta PPG kimia dalam menyusun perangkat perencanaan pembelajaran dengan menggunakan format penilaian. Adapun Langkah-langkah penilaian sebagai berikut:

- Mencermati format penilaian masing-masing instrument pembelajaran yang dinilai 
- Memberi nilai setiap komponen dengan cara membubuhkan tanda cek $(\sqrt{ })$ pada kolom pilihan skor (1 ), (2) dan (3) sesuai dengan penilaian

- Menjumlahkan skor seluruh komponen setelah selesai penilaian

- Menentukan nilai instrument pembelajaran menggunakan persamaan (1) berikut ini:

$$
\text { Nilai }=\frac{\text { Skor yang diperoleh }}{75} \times 100 \%
$$

\begin{tabular}{ll}
\hline PERINGKAT & NILAI \\
\hline Amat Baik (A) & $90 \leq \mathrm{A} \leq 100$ \\
\hline Baik (B) & $75 \leq \mathrm{B}<90$ \\
\hline Cukup (C) & $60 \leq \mathrm{C}<80$ \\
\hline Kurang (K) & $<60$ \\
\hline
\end{tabular}

2. Analisis kemampuan peserta PPG dalam melaksanakan proses pembelajaran yaitu dengan menggunakan lembar observasi. Adapun langkah-langkah penilaian sebagai berikut:

- Memberikan tanda cek $(\sqrt{ })$ pada kolom pilihan YA atau TIDAK sesuai dengan penilaian terhadap penyajian guru model pada saat pelaksanaan pembelajaran

- Memberikan catatan khusus atau saran perbaikan pelaksanaan pembelajaran

- Menghitung jumlah nilai YA dan TIDAK pada komponen yang dinilai yaitu pada tahap pendahuluan, kegiatan inti dan penutup pada saat proses pembelajaran berlangsung

- Menentukan nilai proses pembelajaran menggunakan persamaan (2).

$$
\text { Nilai }=\frac{\text { Jumlah YA }}{40} \times 100 \%
$$

\begin{tabular}{lc}
\hline PERINGKAT & NILAI \\
\hline Amat Baik $(\mathbf{A})$ & $90<\mathrm{AB} \leq 100$ \\
\hline Baik (B) & $80<\mathrm{B} \leq 90$ \\
\hline Cukup $(\mathbf{C})$ & $70<\mathrm{C} \leq 80$ \\
\hline Kurang $(\mathbf{K})$ & $\leq 70$ \\
\hline
\end{tabular}

\section{b. Data kualitatif (Observasi pada tahap plan, open lesson dan refleksi)}

- Pengambilan dokumen pribadi melalui foto

- Pencatatan ucapan dan tindakan yang terjadi pada saat plan, open lesson dan refleksi

- Data yang diperoleh dianalisis setiap tahap pelaksanaan Lesson Study 


\section{HASIL DAN PEMBAHASAN}

Foto pelaksanaan bimbingan oleh dosen pembimbing dalam menerapkan LSLC disekolah dapat dilihat pada Gambar 1. Terlihat peserta PPG aktif bertanya dan selalu mengikuti bimbingan yang dilakukan setiap hari selasa.

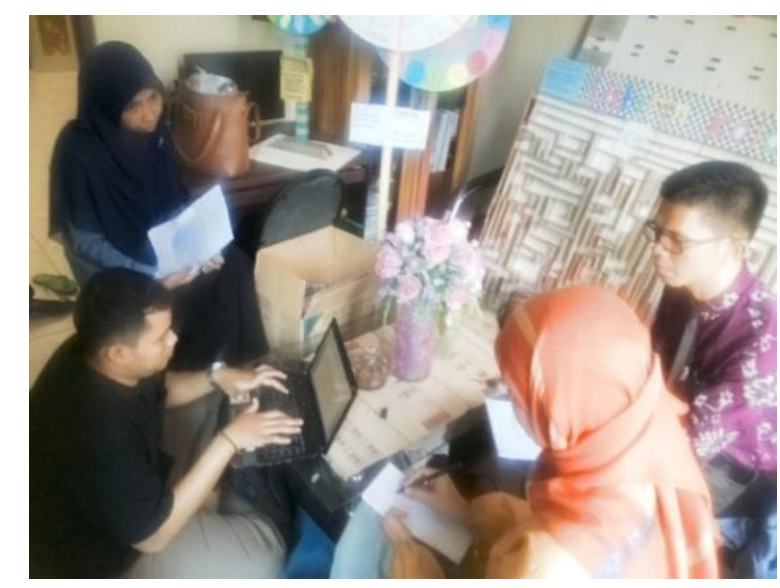

Gambar 1. Foto bimbingan LSLC untuk peserta PPG kimia yang melaksanakan PPL di

\section{SMAN 12 Pekanbaru}

Keberhasilan pelaksanaan pembelajaran sangat tergantung pada kualitas perencanaan pembelajaran yang mengacu pada Standar Isi. Menurut Kunandar, 2013, perencanaan pembelajaran meliputi penyusunan Rencana Pelaksanaan Pembelajaran (RPP), perangkat penilaian dan skenario pembelajaran. Hasil analisis RPP yang telah disusun oleh peserta PPG kimia setiap tahap plan, dapat dilihat pada Tabel 1. Terlihat bahwa peringkat RPP yang dibuat peserta PPG kimia mengalami peningkatan kategori dari B (Baik) pada plan I dan II menjadi A (Sangat Baik) pada plan III.

RPP dengan pokok bahasan Termokimia dan Elektrolisis mendapatkan peringkat sama yaitu B (Baik). Hasil ini terjadi karena RPP pokok bahasan Termokimia dan Elektrolis dalam pemilihan sumber belajar dan media belajar belum sesuai atau sesuai sebagian serta belum menampilkan secara keseluruhan tentang skenario pembelajaran. Mengenai penilaian sebagian soal belum sesuai dengan indikator pencapaian kompetensi serta penskoran penilaian kurang lengkap.

Tabel 1. Hasil analisis penilaian RPP setiap tahap plan

\begin{tabular}{ccc}
\hline Plan & Pokok Bahasan yang dinilai & Peringkat/Nilai \\
\hline I & Termokimia & $\mathrm{B} / 86,667$ \\
\hline II & Elekrolisis & $\mathrm{B} / 83,333$ \\
\hline III & Kinetika kimia & $\mathrm{A} / 93,333$ \\
\hline
\end{tabular}


Dokumentasi tahap pelaksanaan open lesson yang telah dilakukan oleh peserta PPG Pendidikan Kimia dan dosen pembimbing dapat dilihat pada Gambar 2.

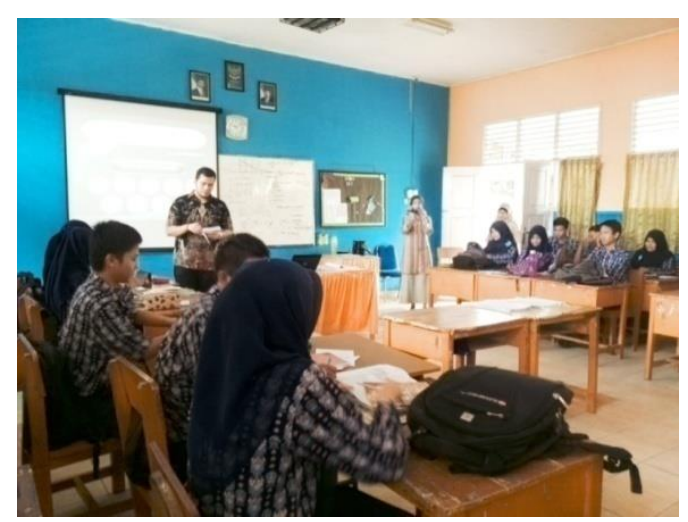

Gambar 2. Foto salah satu guru model (peserta PPG Pendidikan Kimia) melakukan open lesson

Hasil analisis pelaksanaan pelaksanaan pembelajaran yang dilakukan oleh peserta PPG Pendidikan Kmia di SMAN 12 Pekanbaru dapat dilihat pada Tabel 2. Terlihat kompetensi peserta PPG Pendidikan Kimia FKIP Universitas Riau dalam pelaksanaan pembelajaran menunjukkan peningkatan dari kategori K (Kurang) pada open lesson I dan II menjadi C (cukup) pada open lesson III.

Tabel 2. Hasil analisis pelaksanaan open Lesson yang telah dilakukan peserta PPG Pendidikan Kimia FKIP Universitas Riau

\begin{tabular}{ccllc}
\hline $\begin{array}{c}\text { Open } \\
\text { Lesson }\end{array}$ & $\begin{array}{c}\text { Guru } \\
\text { Model }\end{array}$ & Hari/Tanggal & $\begin{array}{c}\text { Pokok Bahasan yang } \\
\text { dinilai }\end{array}$ & Peringkat/Nilai \\
\hline I & MED & $\begin{array}{l}\text { Sabtu/10 } \\
\text { Oktober } 2015\end{array}$ & $\begin{array}{l}\text { Menghitung } \Delta \mathrm{H} \\
\text { berdasarkan data } \\
\text { energy ikatan }\end{array}$ & $\mathrm{K} / 55,0$ \\
\hline II & AA & $\begin{array}{l}\text { Kamis/29 } \\
\text { Oktober } 2015\end{array}$ & Hukum Faraday & $\mathrm{K} / 65,0$ \\
\hline III & LFM & $\begin{array}{l}\text { Kamis/5 } \\
\text { November } 2015\end{array}$ & $\begin{array}{l}\text { Persamaan laju reaksi } \\
\text { dan orde reaksi }\end{array}$ & $\mathrm{C} / 75,5$ \\
\hline
\end{tabular}

Hasil pengamatan pada open lesson I dan II terlihat sama yaitu masing-masing mendapat peringkat $\mathrm{K}$, walaupun dari nilai pada open lesson II mengalami peningkatan dari 55,0 menjadi 65,5 tetap pada peringkat K karena nilainya kecil dari 70,0. Sedangkan pada open lesson III terjadi peningkatan peringkat menjadi C. Pada open lesson I dan II guru model belum melakukan sesuatu kegiatan yang terkait dengan materi, belum 
mampu mengkaitkan materi dengan pengetahuan lain, belum bersifat konstektual, pembelajaran belum tersajikan dari yang mudah ke sulit, belum menyajikan kegiatan peserta didik untuk keterampilan analisis.

Kemudian pada saat pelaksanaan pembelajaran, guru model belum mengamati sikap dan perilaku peserta didik, belum melibatkan peserta didik dalam pemanfaatan media pembelajaran, belum menunjukkan sikap terbuka terhadap respon siswa serta belum menumbuhkan kecerian dan antusias peserta didik dalam belajar. Sedangkan pada open lesson III, guru model telah memperlihatkan keterampilan menganalisis bagi siswa, sudah melibatkan siswa dalam pemanfaatan media pembelajaran dan sudah menunjukkan sikap terbuka terhadap respon siswa.

Setelah melakukan open lesson peserta PPG Pendidikan Kimia langsung melakukan refleksi dibawah bimbingan atau arahan dosen pembimbing, foto dokumentasi dapat dilihat pada Gambar 3.

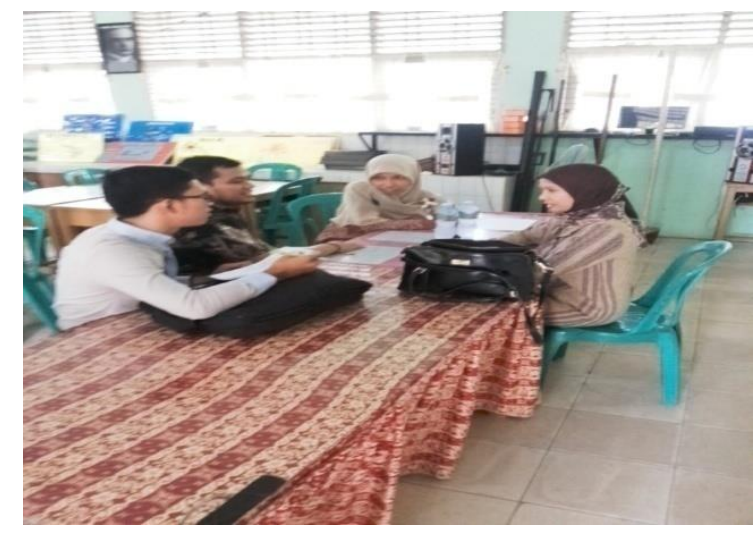

Gambar 3. Foto peserta PPG kimia FIKP Universitas Riau melakukan refleksi bersama dosen pembimbing

Peserta PPG kimia FKIP Universitas Riau (observer) dapat mengungkapkan hasil pengamatannya pada saat open lesson, dapat dilihat pada setiap hasil refleksi berikut :

1. Hasil refleksi I adalah sebagai berikut:

- Siswa kelihatan tidak mengerti pada saat guru memberikan apersepsi

- Bahan ajar yang dibagikan oleh guru tidak semua siswa membacanya

- Siswa membaca bahan ajar ketika guru menjelaskan materi didepan kelas

- Siswa tidak percaya diri untuk mengungkapkan pendapatnya

- Siswa binggung mengerjakan LKPD (Lembar Kerja Peserta Didik)

- Suasana kelas rebut

- Ada dua kelompok tidak dibimbing oleh guru 
- Hanya beberapa siswa yang dapat mengerjakan soal yang diberikan guru

2. Hasil refleksi II adalah sebagai berikut:

- Siswa umumnya membaca bahan ajar secara individu

- Ada 1 kelompok tidak melakukan diskusi

- Ada satu siswa pada saat belajar bermain HP

- Ada satu siswa senang mengajari temannya

- Kondisi kelas rebut

3. Hasil refleksi III adalah sebagai berikut::

- Siswa memperlihatkan perasaan senang belajar

- Siswa sudah berinterkasi dengan guru secara aktif untuk menanyakan materi pada bahan ajar yang dibagikan guru

- Ada 1 kelompok yang dari awal sampai akhir tidak melakukan diskusi

Hasil refleksi yang diperoleh dapat digunakan untuk memperbaiki pembelajaran selanjutnya. Sesuai dengan penelitian yang dilaporkan oleh Brian dan Susie (2011), bahwa tahap refleksi pada LS dapat mereview pembelajaran sebelumnya, mengungkapkan masalah-masalah pada hari itu, dapat mengamati siswa bekerja secara individu atau dalam kelompok, mendiskusikan masalah metode dan menyimpulkan poinpoin utama. Menurut Winarsih, dkk (2012) salah satu penyebab peningkatan kompetensi professional guru adalah dengan dilakukannya tahap-tahap refleksi untuk memperbaiki kualitas pembelajaran berikutnya. Hasil ini diperkuat dengan pendapat Myers (2012) bahwa LS merupakan fasilitas preservice bagi guru untuk melakukan refleksi pembelajaran.

Berdasarkan arahan dosen pembimbing, para peserta PPG Pendidikan Kimia yang melakukan praktek mengajar di SMAN 12 Pekanbaru telah melakukan tindak lanjut perbaikan pembelajaran sebagai berikut:

1. Posisi duduk siswa pada awal pembelajaran sudah membentuk huruf $U$ dua lapisan agar siswa lebih fokus dalam belajar dan guru mudah mengelola kelas walaupun siswa dikelompokkan

2. Peserta PPG Pendidikan Kimia sudah mengenal nama dan karakter setiap siswa, hal ini menunjukkan peserta PPG kimia peduli terhadap siswanya. Hasil penelitian Elvinawati, 2012 menunjukkan bahwa dengan menerapkan $L S$ dapat membantu membangun karakter peserta didik. 
3. Peserta PPG Pendidikan Kimia saling belajar untuk memperbaiki pembelajaran dengan cara menganalisis model-model pembelajaran yang diterapkan dalam pembelajaran

Hasil penelitian ini menunjukkan kompetensi profesionalitas peserta PPG Pendidikan Kimia Fkip Universitas Riau dalam melaksanakan LSLC berkembang dengan baik. Seperti diungkapkan oleh Masaaki, 2012 bahwa LSLC dapat berfungsi sebagai salah satu upaya pelaksanaan program in-service training bagi para guru. Upaya tersebut dilakukan secara kolaboratif dan berkelanjutan.

\section{KESIMPULAN}

Berdasarkan hasil dan pembahasan pada penelitian ini dapat disimpulkan sebagai berikut:

1. Kompetensi peserta PPG Pendidikan Kimia dalam menyusun rencara pembelajaran meningkat dari kategori B(Baik) pada tahap plan I dan II menjadi kategori A(Amat baik) pada plan III

2. Kompetensi peserta PPG Pendidikan Kimia dalam pelaksanaan proses pembelajaran mengalami peningkatan dari kategori K (Kurang) pada open lesson I dan II menjadi C (Cukup) pada open lesson III.

3. Peserta PPG Pendidikan Kimia dengan arahan dosen pembimbing dapat melakukan tahap refleksi dengan baik. 


\section{DAFTAR PUSTAKA}

Brian, D and Susie, G. 2011. Japanese Lesson Study: Teacher Professional Development through Communities of Inquiry. Mathematics Teacher Education and Development. Vol. 13.No 1, Pp. 77-93

Elvinawati, Sumpono, dan Hermansyah A. 2012. Lesson Study pada Mata Kuliah Kimia Sekolah I sebagai Upaya Peningkatan Kualitas Pembelajaran dan Pembangunan Karakter (Character Building). Jurnal Exacta. Vol. X. No. 2. Hal. 156-159

Kusnandar, 2013. Penilaian Autentik (Penilaian Hasil Belajar Peserta didik Berdasarkan Kurikulum 2013). PT. Rajagrafindo Persada. Jakarta

Masaaki, S. 2012. Dialog dan Kolaborasi di Sekolah Menengah Pertama Praktek', Learning Community”. PELITA

Myer, J. 2012. Lesson Study as a Means for Facilitating Preservice Teacher Reflectivity. International Journal for the Scholarship of Teaching and Learning. Vol. 6. No.1. http://www.georgiasouthern.edu/ijsotl ( diakses pada 26 Novembe 2015)

Panduan Pelaksana Praktik Pengalaman Lapangan. 2015. FKIP. Universitas Riau

Winarsih, A dan Mulyani, S. 2012. Peningkatan Profesionalisme Guru IPA Melalui Lesson Study dalam Mengembangkan Model Pembelajaran PBI. Jurnal Pendidikan IPA Indonesia. Vol. 1. N0.1. Pp. 43-50 